\title{
El Conflicto en Ucrania: los Intereses de las Grandes Potencias y los Perdedores de Siempre
}

\author{
Ukrainian Crisis: Great Power Interests and the Usual Losers
}

Ignacio Javier Cardone ${ }^{1}$

\begin{abstract}
RESUMEN
El conflicto en Ucrania presenta antecedentes que se remontan al proceso de independencia de este país en 1991. La escalada del conflicto afecta principalmente a Ucrania y a Rusia, y en menor medida puede alcanzar a la Unión Europea; teniendo como principales perdedores a la propia población ucraniana, sea cual sea su origen étnico.
\end{abstract}

Palabras-clave: Ucrania; Crimea; Conflicto Internacional.

\begin{abstract}
The Ukrainian crisis presents a history that goes back up to the independence process of that country in 1991. The conflict escalation affects mainly Ukraine and Russia, with some lesser potential impact on the European Union, with the Ukrainian population as the main losers of the crisis, whatever their ethnic origin are.
\end{abstract}

Key-words: Ukraine; Crimea; International Crisis.

\section{Crimea: un Conflicto de Larga Data}

El alto al fuego acordado por las fuerzas separatistas y el gobierno de Kiev en Ucrania a comienzos de septiembre ha colocado un freno en la escalada de violencia tanto militar, cuanto política (COLON, 2014; S/A, 2014). Sin embargo, es difícil esperar que el acuerdo cristalice en una salida inmediata al conflicto, toda vez que las posiciones adquiridas tornaron difícil un acuerdo mutuamente aceptable.

A pesar de que la importancia que el conflicto ha adquirido hizo con que apareciera a los ojos de la opinión pública como un conflicto reciente alimentado por las

\footnotetext{
1 Graduado en Ciencia Política por la Universidad de Buenos Aires (UBA), alumno de Maestreado del Programa de Pos-Graduación en Ciencia Política de la UFPR, investigador del Núcleo de Estudios e Investigaciones en Relaciones Internacionales (NEPRI) de la UFPR.
} 
ambiciones territoriales del presidente ruso Vladimir Putin, el conflicto por Crimea es un conflicto de larga data.

Sin intentar hacer una revisión extensiva de la historia de Ucrania, podemos ubicar el origen del presente conflicto -particularmente referido a la escisión de la península de Crimea- en el proceso de independencia de este país de la URSS en 1991.

Ya en 1992 James Gow advertía sobre la centralidad que la relación entre Rusia y Ucrania tendría para la seguridad del continente Europeo:

\begin{abstract}
Ucrania Independiente resultará central para la nueva agenda de seguridad de Europa. Esto resultará así tanto a nivel conceptual, como a nivel práctico. A nivel práctico, el futuro del continente en lo referido a seguridad depende, en gran medida, de la relación entre Rusia y Ucrania; las dos Repúblicas más importantes de la Unión Soviética y los más poderosos entre los estados sucesores de esta. Existe un gran peligro en esta relación para toda Europa en cualquiera de los dos extremos de posibilidades: una alianza militar o la guerra. La primera proyectaría una gran sombra armada sobre Europa -en efecto algo parecido a la 'amenaza Soviética'. La segunda significaría una catástrofe inimaginablemente mayor que las guerras en Yugoeslavia, en términos de la escala del conflicto y el número de refugiados. (GOW, 1992, p.253, Traducción Propia)
\end{abstract}

El referéndum para la independencia de Ucrania fue respaldado por una amplia mayoría de la población en general -incluidos los ucranianos de origen étnico ruso- con la sola excepción de Crimea. En esta última región, el apoyo a la independencia fue más limitado $^{2}$ generándose, unos meses más tarde, un movimiento separatista que casi provocó la escisión de la península. Su pertenencia a Ucrania fue finalmente negociada a cambio de un amplio grado de autonomía, configurándose como la única región con estatus de República Autónoma. Desde entonces la región ha sido el epicentro de conflictos por la unidad territorial del país ${ }^{3}$ llevando en 1994-1995 a la designación de un "presidente" de Crimea, el que fue destituido por el entonces presidente ucraniano Leonid Kuchma en 1995.

\footnotetext{
2 En 1991 el referéndum sobre la independencia de Ucrania por regiones arrojó en Crimea un 54,19\% favorable a la independencia y un $57,07 \%$ en Sevastopol, con un grado de participación de $67,5 \%$ en el primer caso y $63,74 \%$ en el segundo. Las cifras son significativamente menores que las registradas en otras regiones del país, con participación entre el 75,01 y 97,1\% (media sobre el total de 84,18\%), y un voto favorable a la independencia de entre 83,86 y 98,67\% (media sobre el total de 90,32\%). Datos extraídos de: <http://www.electoralgeography.com/new/en/countries/u/ukraine/ukraineindependence-referendum-1991.html >. Accedido el 09/09/2014.

${ }^{3}$ Sobre el proceso de independencia de Ucrania y la creación del Estado Ucraniano VER: KUZIO, 1998.
} 
A pesar de que el movimiento separatista de masas colapsó en 1995, su potencial permanecerá en Crimea, permaneciendo también como amenaza a la integridad territorial de Ucrania. Este es especialmente el caso tomando en consideración el hecho de que tres cuartas partes de la opinión pública rusa considera que Crimea y Sevastopol deberían estar bajo soberanía Rusa por derecho propio. (KUZIO, 1998, p.82, Traducción Propia)

Las dificultades en el proceso de creación del Estado-Nación Ucraniano derivan de una conjunción de factores. Factores históricos tales como un pasado en común y la inexistencia de un Estado Ucraniano independiente -a sola excepción de los cuasi estados surgidos durante 1917 y 1921 como consecuencia de la desarticulación del Imperio Ruso, culminando con el triunfo bolchevique y la anexión definitiva de Ucrania a la Unión Soviética-; se conjugan con factores propios de la dinámica de colonización interna de la Unión Soviética, incluyendo la política de integración cultural, política, económica, militar y demográfica (KUZIO, 1998).

Eso determinó una compleja dinámica interna donde podían identificarse, por un lado, una Ucrania más occidental, moderna y con una identidad nacional; y por otro, una Ucrania oriental, más pro-rusa e identificada con el ideal pan-eslavista (KUZIO, 1998). La falta de una identidad nacional, de una estructura institucional y de una moral o ideología de estado significó importantes esfuerzos para la conformación tanto del aparato institucional, cuanto de los contenidos ideológicos y simbólicos de la nacionalidad. La estructura heredada de la Unión Soviética significó tanto la readaptación de sus fuerzas de seguridad, cuanto la necesidad de profundas reformas económicas, las cuales debieron acompasar su ritmo como consecuencia de la necesidad de articular intereses tanto de las viejas elites heredadas del régimen soviético, cuanto de las nuevas elites emergentes del proceso liberalizador (KUZIO, 1998).

En el ámbito externo, la dependencia económica soviética marcó la gran dependencia de Rusia, al tiempo que intentaba abrirse a la economía occidental como forma de integrarse en la nueva economía global, superar la crisis económica y estabilizarse políticamente. La presencia de la flota soviética en el puerto de Sevastopol en la península de Crimea significó la situación más sensible de la transición de la Unión Soviética a la República Independiente, resolviéndose con el permiso Ucraniano de conservación por parte de Rusia de la Base Naval hasta 2042. 
Así, el conflicto entre Rusia y Ucrania, particularmente sobre la Península de Crimea y el Puerto de Sevastopol, constituye un conflicto que remonta sus orígenes hasta el proceso de desintegración de la Unión Soviética en 1991 y que muestra continuidad hasta los días de hoy, agravado por las dificultades de Ucrania para constituirse como un Estado-Nación consolidado.

\section{El Entrecruzamiento de Intereses y la Escalada del Conflicto: ganadores y perdedores.}

De las grandes potencias involucradas en el conflicto, quizá los E.U.A. sea el país que más se beneficia con la crisis en Ucrania.

Si, por un lado, la incorporación de Crimea a la Federación Rusa fue interpretada como una señal de debilidad de los E.U.A. y, más particularmente, del Presidente Obama; por otro la inestabilidad de la región y las sanciones implementadas contra Rusia no parecen afectar significativamente intereses norteamericanos (WALT, 2014; SAKWA, 2014).

Analizado internamente, el conflicto en Ucrania podría fortalecer el sector de los "halcones" reforzando las críticas que el Presidente Obama viene sufriendo como consecuencia de su política exterior.

Por otro lado, la reciente decisión de la OTAN de reforzar la frontera oriental, permite a los E.U.A. contar con una fuerte presencia en la región compartiendo los costos de dicha presencia con sus aliados atlánticos.

En cuanto a la Unión Europea (UE) la situación es mucho más compleja. La inestabilidad en la región significa riesgos importantes en términos de las consecuencias del conflicto y la necesidad de gastos de seguridad. La cantidad de refugiados y ayuda humanitaria que se precisaría, sumados a los costos militarización de la frontera en caso de un enfrentamiento armado a gran escala en Ucrania (sin contar con una intervención directa en el conflicto) son lo suficientemente elevados como para justificar una posición moderada a respecto de la crisis. 
La interdependencia con Rusia es mucho mayor, y particularmente significativa en lo que se refiere a la provisión de gas. Es por eso que hasta el momento, si bien se han ido incrementando y profundizando las sanciones, estas han sido especialmente diseñadas para actuar sobre áreas e intereses específicos que no afecten los propios intereses europeos (SAKWA, 2014).

Por eso, la preocupación de la UE parecería ser doble: por un lado evitar el conflicto a gran escala en la región y, por otro, dar una señal de fuerza a Putin para evitar la repetición de lo sucedido en Georgia y en Ucrania en otros países de la ex URSS.

Rusia es, después de Ucrania, la potencia más afectada por el conflicto. Las sanciones económicas sufridas afectan su economía en un momento de clara debilidad (estancamiento económico e inflación) y el avance de las fronteras de la OTAN y creciente militarización afectan sensiblemente su seguridad.

Entre las opciones disponibles parece poco probable que Rusia se retire de Crimea o acepte cualquier salida al conflicto en lo restante del territorio Ucraniano que no contemple, al menos mínimamente, sus intereses de seguridad y la de los ucranianos de origen étnico ruso (MEARSHEIMER, 2014). Como opción política y económica la conformación de un eje con China parece ser la señal de fuerza más clara hasta el momento al tiempo que se pretende dar énfasis a los BRICs como polo alternativo al de las potencias occidentales (ROSSI, 2014). De cualquier modo, la capacidad que estas medidas tienen para moderar los impactos negativos sobre la economía rusa y el "cerco" político instalado por occidente parece muy limitada, al menos en el corto y mediano plazos.

Ucrania, por su parte, es el claro perdedor de la crisis. Con una parte del territorio perdido, su economía duramente afectada, y una grande cantidad de muertos en el conflicto armado entre las fuerzas oficiales y las fuerzas separatistas ${ }^{4}$, el saldo se revela como claramente negativo, en una nación que presentaba ya problemas sociales.

Una vez considerada como proyecto de nación multiétnica y multicultural, hoy Ucrania se divide en una lucha intestina que separa y enfrenta dos sectores sociales que, al menos en un comienzo, se presentaban como favorables a un proyecto compartido de

\footnotetext{
${ }^{4}$ Cifras preliminares contabilizan entre 2500 y 3000 muertes hasta el momento.
} 
nación, con la excepción de Crimea. En este sentido, un análisis más pormenorizado de la evolución en las condiciones sociales, económicas y políticas se presenta como necesario para una mejor comprensión de las condiciones que desataron el conflicto político interno. En términos generales, analizadas las cifras desde 1991 (VER GRÁFICO 1) vemos que, luego de un periodo inicial de retroceso, el Ingreso Nacional Bruto per capita registra un crecimiento sostenido desde el año 2000, con la sola excepción del período 2008-2009 (concomitante con la crisis económica internacional), alcanzando en 2013 un valor de 2,6 veces el valor de 1991 (en dólares constantes). Por el contrario el índice GINI (VER GRÁFICO 2) aparece con un valor significativamente mayor en 1995 y 1996, para luego descender nuevamente hasta alcanzar en 2010 un valor casi idéntico al de 1991. Por su parte el Índice de Desarrollo Humano (IDH), presenta un importante retroceso en el período 1990-2000, recuperándose a partir de entonces, registrando una disminución sólo en el período 2009-2010. Sin embargo, cuando relativizado el crecimiento del IDH en el contexto global ${ }^{5}$, vemos que en general Ucrania presenta una caída en el período 1990-2000, con un estancamiento relativo en el período posterior, a sola excepción de los años 2005 y 2008 donde esa diferencia se incrementa, para volver a los valores anteriores con posterioridad. Esto explica la caída de cinco lugares en el ranking mundial en los últimos cinco años.

Lo anterior indica, de algún modo, una creciente concentración de la riqueza, lo que podría explicar la insatisfacción política y la polarización de las posiciones de los dos sectores sociales hoy enfrentados.

\footnotetext{
${ }^{5}$ La comparación con el Índice Global nos permite, a nuestro entender, tener una mejor aproximación a las percepciones que la población tiene sobre esas mejoras en las condiciones de vida, neutralizando en cierta medida las mejoras estructurales (propias de los avances tecnológicos y otros). Si bien es cierto que otras consideraciones deberían ser realizadas para una afirmación sobre esas percepciones, la comparación nos parece, como mínimo, útil y relevante.
} 
GRAFICO 1: INGRESO NACIONAL BRUTO PER CAPITA, ATLAS METHOD (US\$ CONSTANTES): UCRANIA 1991-2013

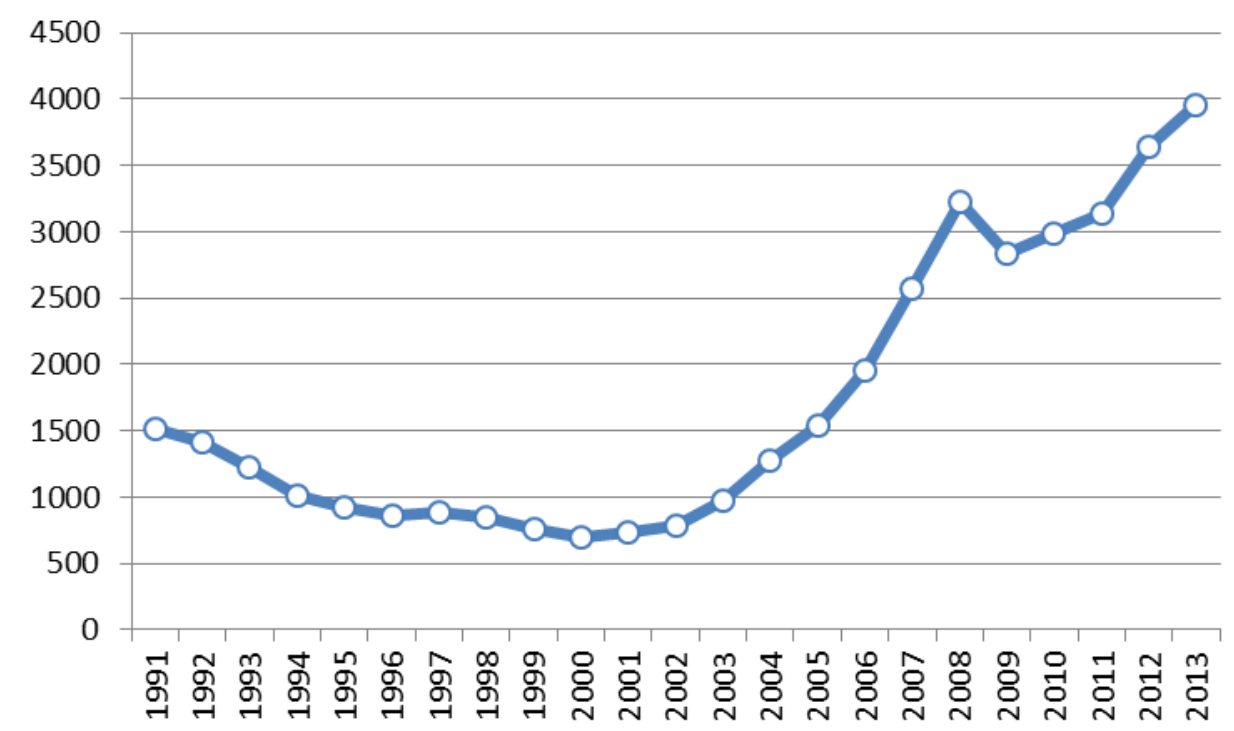

Fuente: Elaboración Própia en base a datos del Banco Mundial $<$ http://databank.worldbank.org>

GRAFICO 2: ÍNDICE GINI: UCRANIA 1991-2013

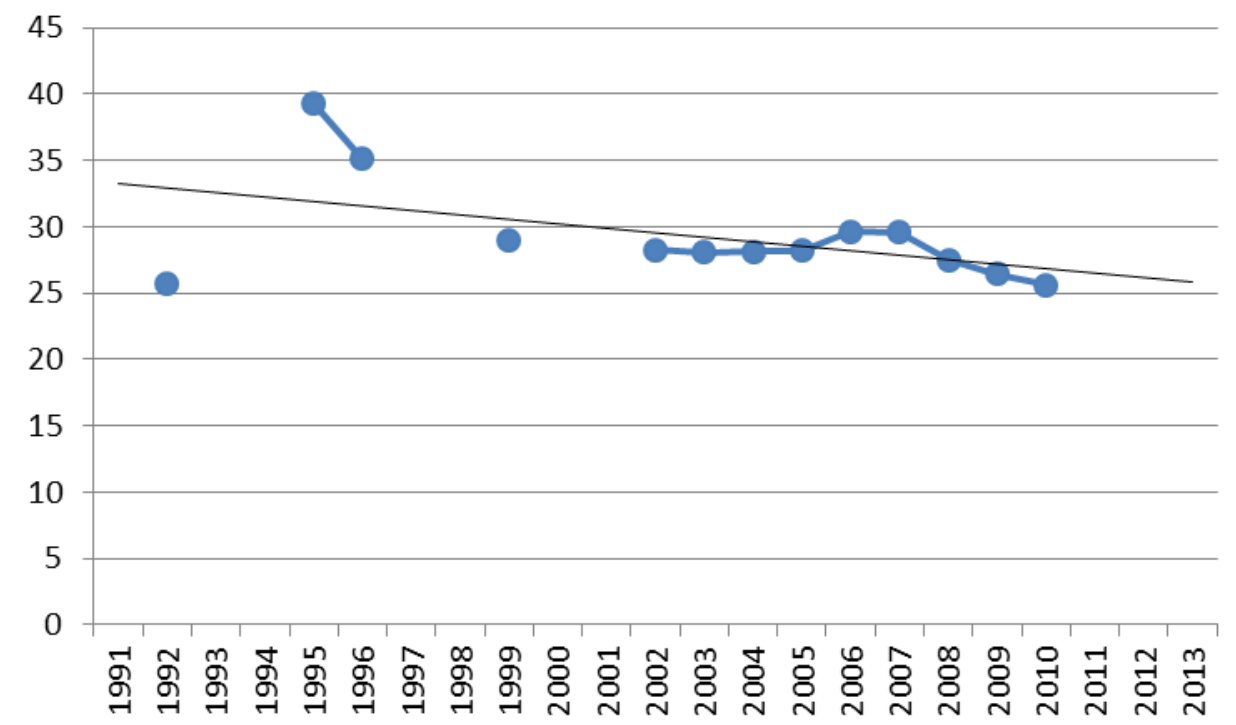

Fuente: Elaboración Própia en base a datos del Banco Mundial $<$ http://databank.worldbank.org> 
GRÁFICO 3: ÍNDICE DE DESARROLLO HUMANO (IDH)- PNUD: UCRANIA y MUNDIAL 1990-2013

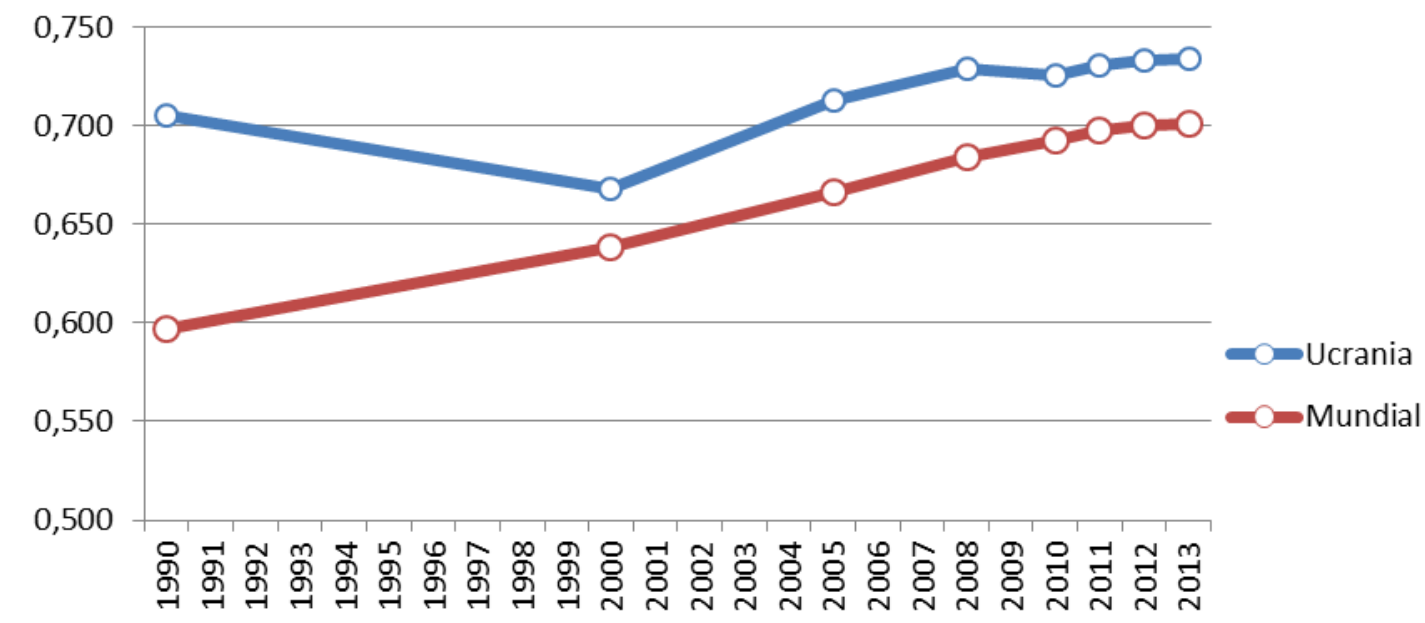

Fuente: Elaboración Própia en base a datos del PNUD

$<$ http://hdr.undp.org/es/data>

El desarrollo del conflicto y los costos asociados (particularmente los prejuicios económicos derivados de acuerdos especiales con Rusia), difícilmente contribuyan a mejorar la situación económica y social, mientras que el enfrentamiento social sobre bases étnicas puede derivar en divisiones sociales duraderas que cristalicen en conflictos políticos de larga proyección. La creación de un área de libre comercio entre Ucrania y la UE y los programas de ayuda occidentales (ROSTYSLAV, 2014), aunque consigan moderar los efectos negativos enunciados, difícilmente consigan revertir dichos efectos. Considerados los efectos de incorporación de otros países a la UE (como el caso de Grecia), las expectativas de que dicha alianza desemboque en un mayor nivel de desarrollo y de gobernanza democrática, parecen injustificadas.

\section{Referencias Bibliográficas}

BANCO MUNDIAL. World DataBank. Disponível em: < http://databank.worldbank.org> COLON, Leandro. Ucrânia e rebeldes anunciam cessar-fogo. Folha de São Paulo. San Pablo: 6 de Sep. 2014. 
GOW, James. Independent Ukraine: the Politics of Security. International Relations. I.3, V.11: 253-267, Dic. 1992.

KUZIO, Taras. Ukraine: State and Nation Building. London: Routledge, 1998.

MEARSHEIMER, John J. Getting Ukraine Wrong. New York Times. 13 de Mar. 2014.

PNUD (Programa das Nações Unidas para o Desenvolvimento). Human Development Reports. Human Development Index. Disponível em: < http://hdr.undp.org/es/data>

ROSSI, Clóvis. 0 início de um eixo anti-EUA. Folha de São Paulo. San Pablo: 22 de May. 2014.

ROSTYSLAV, Tronenko. Associação com UE ajudará a implantar reformas na Ucrânia. Folha de São Paulo. San Pablo: 26 de Jun. 2014.

SAKWA, Richard. The Politics of US and EU Sanctions on Russia's Energy Sector. EInternational Relations. 15 de Ago. 2014.

WALT, Stephen. No Contest. Foreign Policy. 3 de Marzo de 2014.

S/A. Cessar-fogo no leste da Ucrânia é mantido após denúncias de violação. Folha de São Paulo. San Pablo: 8 de Sep. 2014. 